\title{
Technically recoverable methane hydrate potential of the marine regions in the exclusive economic zones of Turkey
}

\author{
Sukru Merey ${ }^{1 *}$ \\ ${ }^{1}$ Batman University, Department of Petroleum and Natural Gas Engineering, Merkez Kampüsü, 72100, \\ Batman, Turkey
}

\begin{abstract}
The present study was carried out to determine technically recoverable methane hydrate potential of the marine regions in the exclusive economic zones (EEZ) of Turkey by using the algorithm developed and Monte Carlo simulation method. It was found that technically recoverable methane in methane hydrate-bearings in the EEZ of Turkey is approximately 12.08 standard trillion cubic meters $(\mathrm{tcm})$. These reserves are in the Black Sea and the Eastern Mediterranean Sea within the EEZ of Turkey. Although there are some thermogenic gas hydrate potentials in the Sea of Marmara, the EEZ of Turkey in the Sea of Marmara and the Aegean Sea (or the Sea of Islands) do not have any technically recoverable methane hydrate potential at current technological conditions.
\end{abstract}

\section{Introduction}

Gas molecules and water molecules form ice-like structures called gas hydrates at low temperature and high pressure conditions. Thus, gas hydrates exist in marine environment (mostly) and permafrost regions all over the world, which are significant energy resources [1]. Even with conservative estimates, it is considered that technically recoverable methane $\left(\mathrm{CH}_{4}\right)$ amount within methane hydrate-bearing sands in the world is approximately 1226 standard trillion cubic meters (tcm) [2]. Thus, after 2000s, there have been many gas hydrate exploration activities and gas hydrate production trials. In Canada, Japan, USA and China, gas hydrate production trials were implemented [1]. In Turkey, there is an early interest to gas hydrates. Although there are several experimental studies and geophysical explorations in the Black Sea, more efforts for gas hydrate exploration studies are essential in Turkey as in the most part of the world. Initially, it is essential to indicate gas hydrate potential with reserve estimations.

Methane hydrate reserve estimation is very crucial to indicate this potential at a certain location. Although there are some studies estimating methane hydrate potential in the whole parts of the Black Sea and the Mediterranean Sea [3, 4], currently there is no study estimating technically recoverable methane hydrate potential in the exclusive economic zones (EEZ) in the Black Sea, the Sea of Marmara, the Aegean Sea and the Mediterranean Sea of Turkey. Thus, this was aimed in this study because methane hydrate potential in

*Corresponding author: sukru.merey@batman.edu.tr 
these regions might decrease the dependency of Turkey on imported natural gas. More than $99 \%$ of natural gas demand (50-55 billion standard $\mathrm{m}^{3}$ per year) of Turkey is supplied by mostly Russia, Iran, Azerbaijan, Nigeria, Algeria, etc [3].

\section{Material and methods}

In all gas hydrate exploration projects, initially it is aimed to estimate gas hydrate reserve potentials in their study areas. Although a few geophysical explorations were conducted in the Black Sea, Turkey has only early interests to gas hydrates. Thus, it is important to reveal technically recoverable methane hydrate potentials of Turkey.

$$
\begin{gathered}
O G I P=\gamma \cdot S_{h} \cdot h \cdot A \cdot E F \cdot C R ; \\
E F=\frac{M W_{C H_{4}}}{M W_{C H_{4}}+N_{H} M W_{H_{2} O}} \cdot \frac{V_{H} \cdot \rho_{H}}{\rho_{C H_{4}}},
\end{gathered}
$$

where $O G I P$ - original $\mathrm{CH}_{4}$ in-place in hydrates, standard $\mathrm{m}^{3} ; \psi$-porosity; $S_{h}$-hydrate saturation; $h$-thickness of hydrate zone, $\mathrm{m} ; A$ - cross-sectional area of hydrate zone, $\mathrm{m}^{2}$; $C R$ - cavity fill ratio of $\mathrm{CH}_{4} ; E F$ - expansion factor of $\mathrm{CH}_{4}$ in hydrate to surface standard conditions; $M W_{\mathrm{CH} 4}-$ molecular weight of $\mathrm{CH}_{4}, \mathrm{~g} / \mathrm{mol} ; M W_{\mathrm{H} 2 \mathrm{O}}-$ molecular weight of $\mathrm{H}_{2} \mathrm{O}$, $\mathrm{g} / \mathrm{mol} ; N_{H}$ - hydration number of $\mathrm{CH}_{4}$ hydrate; $V_{H}$ - unit hydrate volume $\left(1 \mathrm{~m}^{3}\right) ; \rho_{H}-\mathrm{CH}_{4}$ hydrate density, $\mathrm{kg} / \mathrm{m}^{3} ; \rho_{\mathrm{CH} 4}: \mathrm{CH}_{4}$ gas density at standard conditions $\left(0.717935 \mathrm{~kg} / \mathrm{m}^{3}\right.$ at $0^{\circ} \mathrm{C}$ and $\left.1 \mathrm{~atm}\right)$.

Common gas hydrate reserve estimation formulas (Equation 1 and Equation 2) [3, 5, 6] were used in this study to estimate gas hydrate reserve potential in the exclusive economic zones (EEZ) of Turkey in the Black Sea, the Sea of Marmara, the Aegean Sea and the Eastern Mediterranean Sea. In these formulas, gas hydrate properties and methane hydrate stability zone (MHSZ) thickness are essential parameters. Hence, by using the algorithm in Fig. 1, these parameters were estimated for the Black Sea, the Sea of Marmara, the Aegean Sea, and the Eastern Mediterranean Sea.

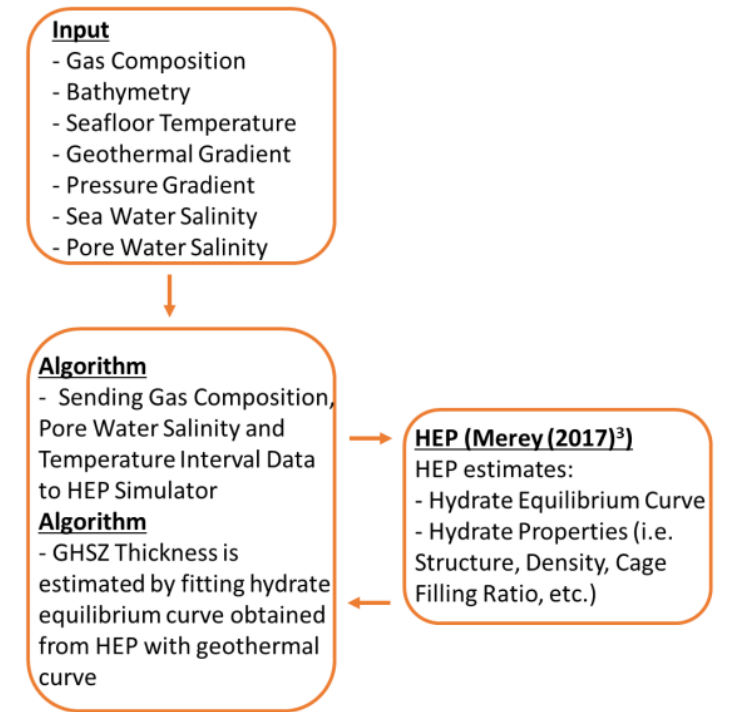

Fig. 1. Methane or gas hydrate stability zone (MHSZ or GHSZ) estimation algorithm. 
It is known that gas hydrate samples were collected in the Black Sea, the Sea of Marmara, and the Eastern Mediterranean Sea. Moreover, there are many indications (i.e. gas seeps, mud volcanoes, seismic, etc.) of gas hydrate existence in these seas [3-5]. In this study, a detailed literature survey about the Black Sea, the Sea of Marmara, the Aegean Sea and the Mediterranean Sea was completed in order to collect essential data (i.e. bathymetry, geothermal gradient, pressure gradient, seafloor temperature, salinity, etc.) for the gas hydrate reserve estimations (Fig. 1) [3, 5, 7-14].

\section{Results and discussion}

In this study, by using the algorithm in Fig. 1, initially MHSZ thickness below seafloor in the Black Sea was estimated. Then, Fig. 2 was drawn including the EEZ border of Turkey in the Black Sea. Fig. 2a shows the bathymetry and gas hydrate indicators in the Black Sea. According to the map generated in Fig. 2b, the maximum MHSZ thickness below seafloor in the Black Sea is nearly $406 \mathrm{~m}$ with an average thickness of $266 \mathrm{~m}$. As an average, methane hydrate formation in the Black Sea starts (as water depth) at nearly $675 \mathrm{~m}$ below sea level (mbsl). There are many indications of methane hydrates (i.e. methane hydrate samples, bottom-simulating reflections, gas seeps, etc.) in the Black Sea.
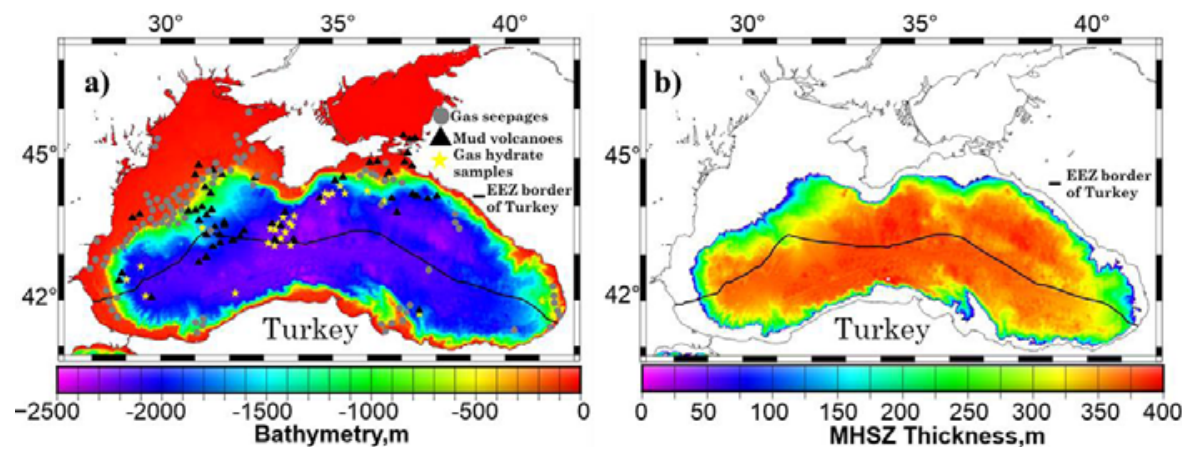

Fig. 2. Bathymetry and gas hydrate indicators of the Black Sea (a); MHSZ thickness below seafloor in the Black Sea (b).

Thus, the EEZ of Turkey in the Black Sea has a great potential in terms of methane hydrates. In this study, Monte Carlo simulations were conducted by using the reserve estimation equations of Boswell and Collett [6]. MHSZ thickness in Fig. 2b is one of the most important parameters for gas hydrate reserve estimations. Almost all the countries in the world focus on methane hydrates deposited inside coarse sands because of their higher porosity and permeability values. Therefore, the methane amounts in methane hydrates deposited in all sediments and methane hydrates in coarse sands were calculated. In the EEZ of Turkey in the Black Sea, the total expected methane in methane hydrates deposited inside all sediments is approximately $114.2 \mathrm{tcm}$ (ranging from 3.73 to $411.55 \mathrm{tcm}$ ). On the other hand, the methane amount in methane hydrate-bearing sands (which are considered as technically recoverable gas hydrates) in the EEZ of Turkey in the Black Sea was found as $4.63 \mathrm{tcm}$ (varying from 0.114 to $16.87 \mathrm{tcm}$ ). In August 2020, Turkey announced that more than 100 meters of natural gas bearing reservoir in Pliocene and Miocene sands were discovered in Tuna- 1 well $\left(42^{\circ} 50^{\prime} 21.55^{\prime \prime} \mathrm{N} / 31^{\circ} 17^{\prime} 21.37^{\prime \prime} \mathrm{E}\right)$ at a water depth of $2115 \mathrm{~m}$ and $1000 \mathrm{mbsf}$ (meter below seafloor). The reserve potential is considered to be nearly 320 standard billion $\mathrm{m}^{3}$ of natural gas (mostly methane). As seen in Fig. 2a, there are many mud volcanoes near Tuna-1 coordinates. These conventional gas and sands in the Black Sea also shows the high potential of source gas and methane hydrate-bearing sands within MHSZ. 
The Sea of Marmara is an inland sea connecting the Aegean Sea and the Black Sea. This sea is completely within the EEZ of Turkey. The Sea of Marmara is located in a tectonically very active area. There have been many shallow coring and gas sampling studies in the Sea of Marmara $[5,12]$. The average and maximum water depths in the Sea of Marmara are 297 and 1288 m, respectively (Fig. 3a) [14]. Fig. 3a indicates gas hydrate indicators and bathymetry of the Sea of Marmara. Due to the shallow water depth and high seafloor temperature $\left(\sim 13.5^{\circ} \mathrm{C}\right)$ in the Sea of Marmara, methane hydrate (100\% methane) cannot exist. For this reason, MHSZ thickness is zero as seen in Fig. $3 b$ in the Sea of Marmara. In the Sea of Marmara (Western High Section), thermogenic origin gas hydrate sample was collected. Moreover, many thermogenic gas samples were collected [12]. The average of these gas compositions include $90.347 \% \mathrm{CH}_{4}$ (methane), 6.518\% $\mathrm{CO}_{2}$ (carbon dioxide), $0.677 \% \mathrm{C}_{2} \mathrm{H}_{6}$ (ethane), $1.451 \% \mathrm{C}_{3} \mathrm{H}_{8}$ (propane) and other impurities. With this average gas composition, mixed gas hydrate (sII type) can form in the conditions of the Sea of Marmara. Then, GHSZ (gas hydrate stability zone) thickness of this gas composition was estimated by implementing the algorithm in Fig. 1. In Fig. 3c, the GHSZ thickness map of this gas composition is shown in the Sea of Marmara. It was found that the maximum and average GHSZ thickness for this gas composition are 107.6 and $61 \mathrm{~m}$, respectively. By using the algorithm in Fig. 1 and GHSZ thickness in Fig. 3b, Monte Carlo simulation was conducted for reserve estimation. The amount of the gas composition $\left(90.347 \% \mathrm{CH}_{4}\right.$, $6.518 \% \mathrm{CO}_{2}, 0.677 \% \mathrm{C}_{2} \mathrm{H}_{6}, 1.451 \% \mathrm{C}_{3} \mathrm{H}_{8}$ and other impurities) in its gas hydrates deposited in all sediments in the Sea of Marmara was found as nearly 289.1 standard billion cubic meters $(\mathrm{bcm})(18.81-1237.9 \mathrm{bcm})$. Inside coarse sands in the Sea of Marmara, this reserve was estimated as $116.5 \mathrm{bcm}(1.52-725.5 \mathrm{bcm})$. Compared to methane hydrates, thermogenic hydrates are more stable so it is more difficult to dissociate thermogenic hydrates. Moreover, methane hydrates are common in nature. For this reason, currently all countries in the world targets methane hydrates for feasible gas production.

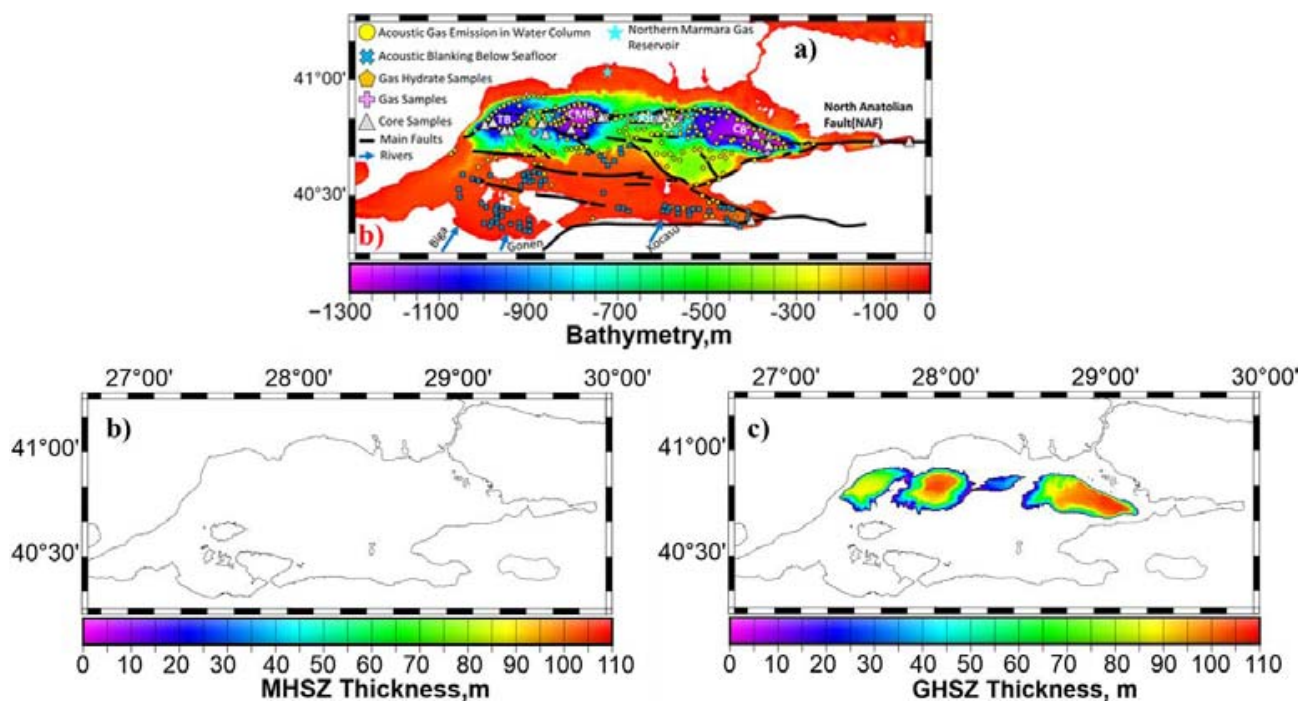

Fig. 3. Bathymetry and gas hydrate indicators in the Sea of Marmara (a); MHSZ thickness in the Sea of Marmara (b); GHSZ (for average gas composition) thickness in the Sea of Marmara (c).

The Aegean Sea (or the Sea of Islands) is an elongated embayment of the Mediterranean Sea located between the Greek peninsula and Turkish peninsula as seen in Fig. 4. Although there are some places with a water depth $3544 \mathrm{~m}$, the average water depth in the Aegean Sea is approximately $322 \mathrm{~m}$ (Fig. 4a) [14]. 

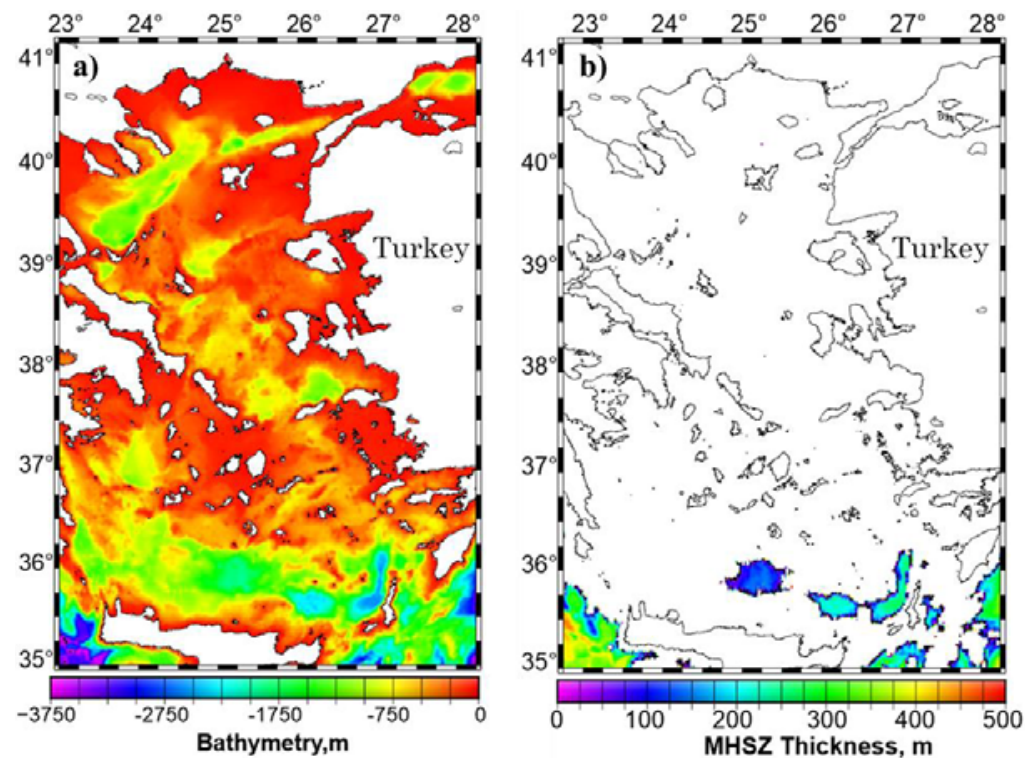

Fig. 4. Bathymetry of the Aegean Sea (a); MHSZ thickness in the Aegean Sea (The Sea of Islands) (b).

Even though there are some gas hydrate indications (i.e. mud volcano, gas seepages, pockmarks, etc) $[9,13]$, the Aegean Sea might be considered in a paucity of methane hydrates and gas hydrates. Due to the shallow water depth and higher seafloor temperature, MHSZ thickness within the EEZ of Turkey in the Aegean Sea in Fig. 4b was found mostly zero. Moreover, there is no indication or study of extensive thermogenic gas releases in the Aegean Sea for possible thermogenic gas hydrate existence as the Sea of Marmara.

Turkey's EEZ border in the Eastern Mediterranean Sea is shown in Fig. 5. As seen in Fig. 5a, the maximum and average water depths are 4502.9 and $1950 \mathrm{~m}$, respectively [14]. Higher water depth is an advantage for thicker MHSZ due to high hydrostatic pressure. By using the algorithm in Fig. 1, Fig. 5 was obtained for some part of the Eastern Mediterranean Sea. In Fig. 5b, the maximum MHSZ thickness and average MHSZ thickness were found as 471 and $227 \mathrm{~m}$, respectively. Generally, methane hydrate formation starts below $1390 \mathrm{mbsl}$ (meter below sea level) in Fig. 5. Monte Carlo simulations were held for methane hydrate reserve estimation in the Eastern Mediterranean Sea within the EEZ of Turkey.
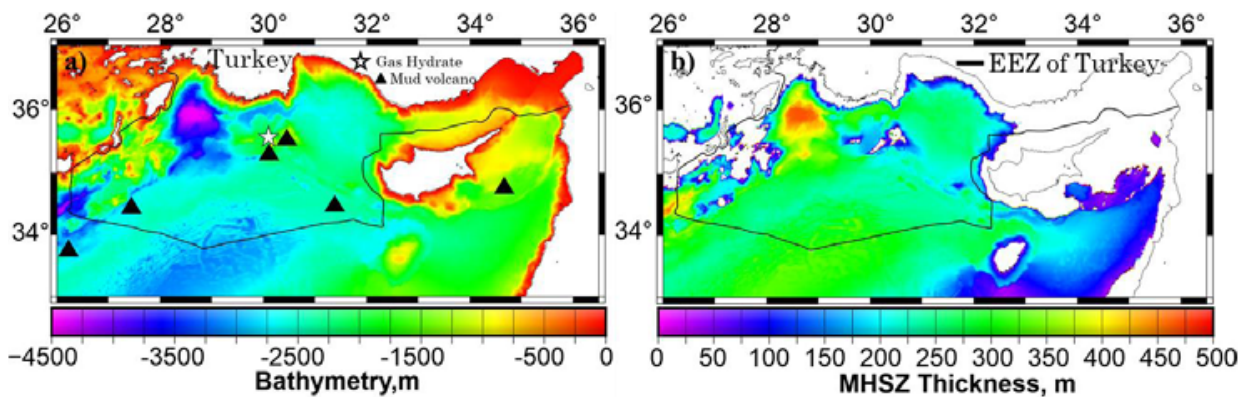

Fig. 5. Bathymetry and gas hydrate indicators in some part of the Eastern Mediterranean Sea (a); MHSZ thickness in some part of Eastern Mediterranean Sea (b). 
In the EEZ of Turkey in the Eastern Mediterranean Sea in Fig. 5b, the total expected methane amount in methane hydrates deposited inside all sediments is approximately $68.16 \mathrm{tcm}$ (ranging from 0.904 to $397.86 \mathrm{tcm}$ ). On the other hand, the methane amount in methane hydrate-bearing sands (which are considered as technically recoverable gas hydrates) in the EEZ of Turkey in the Eastern Mediterranean Sea was found as nearly $7.45 \mathrm{tcm}$ (varying from 0.045 to $51.3 \mathrm{tcm}$ ).

In this study, MHSZ thicknesses of the Black Sea, the Sea of Marmara, the Aegean Sea (the Sea of Islands) and the Eastern Mediterranean Sea in the EEZ of Turkey were estimated by using the algorithm in Fig. 1. Then, Monte Carlo simulations were held to estimate methane amount in methane hydrate-bearing sediments/sands of the marine regions in the EEZ of Turkey. In Table 1, the estimated methane amounts in methane hydrate-bearing sediments of the marine regions in the EEZ of Turkey were summarized for the Black Sea, the Sea of Marmara, the Aegean Sea and the Mediterranean Sea. According to this estimation, Turkey might have $182.36 \mathrm{tcm}(4.634-809.41 \mathrm{tcm})$ of methane in methane hydrate-bearing sediments. Technically recoverable methane amount in methane hydrate-bearing sands in the marine regions within the EEZ of Turkey is nearly $12.08 \mathrm{tcm}(0.159-68.17 \mathrm{tcm})$ as seen in Table 2.

Table 1. Estimated methane amount in methane hydrate-bearing sediments of the marine regions in the EEZ of Turkey.

\begin{tabular}{|l|c|c|c|}
\hline \multicolumn{1}{|c|}{ Location } & Minimum, tcm & Mean, tcm & Maximum, tcm \\
\hline The Black Sea & 3.73 & 114.2 & 411.55 \\
\hline The Sea of Marmara & - & - & - \\
\hline The Aegean Sea (The Sea of Islands) & - & - & - \\
\hline The Eastern Mediterranean Sea & 0.904 & 68.16 & 397.86 \\
\hline
\end{tabular}

Table 2. Estimated methane amount in methane hydrate-bearing sands of the marine regions in the EEZ of Turkey.

\begin{tabular}{|l|c|c|c|}
\hline \multicolumn{1}{|c|}{ Location } & Minimum, tcm & Mean, tcm & Maximum, tcm \\
\hline The Black Sea & 0.114 & 4.63 & 16.87 \\
\hline The Sea of Marmara & - & - & - \\
\hline The Aegean Sea (The Sea of Islands) & - & - & - \\
\hline The Eastern Mediterranean Sea & 0.045 & 7.45 & 51.3 \\
\hline
\end{tabular}

Methane hydrate cannot exist in the Sea of Marmara but there are many thermogenic gas seepages. According to the estimation with average gas composition $\left(90.347 \% \mathrm{CH}_{4}\right.$, $6.518 \% \mathrm{CO}_{2}, 0.677 \% \mathrm{C}_{2} \mathrm{H}_{6}, 1.451 \% \mathrm{C}_{3} \mathrm{H}_{8}$ and other impurities) in this study, there might be $0.2891 \mathrm{tcm}$ of this gas within gas hydrate-bearing sediments and $0.1165 \mathrm{tcm}$ of this gas within gas (sII) hydrate-bearing sediments in the Sea of Marmara in Table 3. However, in the world, all gas production trials were conducted for methane hydrates (sI) including almost $100 \% \mathrm{CH}_{4}$. Therefore, the gas hydrate potential in Table 3 for the Sea of Marmara is ignored in terms of technically recoverable methane hydrate potential.

Table 3. Estimated gas amount in gas hydrates in the Sea of Marmara.

\begin{tabular}{|c|c|c|c|}
\hline Sediments & Minimum, tcm & Mean, tcm & Maximum, tcm \\
\hline All & 0.01881 & 0.2891 & 1.2379 \\
\hline Sand & 0.00152 & 0.1165 & 0.7255 \\
\hline
\end{tabular}

Briefly, in this study, an algorithm in Python language was developed in order to predict MHSZ or GHSZ thickness in the conditions of the Black Sea, the Sea of Marmara, the 
Aegean Sea and the Eastern Mediterranean Sea within the EEZ of Turkey. Then, Equation 1 and Equation 2 were implemented inside the Monte Carlo algorithm. Then, finally methane hydrate potential in all sediments and coarse sands were predicted. This study is the first study directly aiming to estimate methane amount deposited in methane hydrates in the marine environment in the EEZ of Turkey.

\section{Conclusions}

In this study, initially MHSZ thicknesses below seafloor were estimated in the EEZ of Turkey in the Black Sea, the Sea of Marmara, the Aegean Sea and the Mediterranean Sea Then, with Monte Carlo simulations, methane hydrate reserve estimations were conducted. In conclusion, Turkey has high potential of technically recoverable methane in methane hydrates in the EEZ of Turkey in the Black Sea and the Eastern Mediterranean Sea. This amount is $12.08 \mathrm{tcm}$ as a mean. Turkey imports more than $99.5 \%$ of its natural gas from different countries (i.e. Russia, Iran, Azerbaijan, etc.). Hence, $12.08 \mathrm{tcm}$ of methane potential might supply Turkey's natural gas demand significantly. This amount is a good motivation for Turkey to implement extensive gas hydrate exploration projects. Yet, gas hydrate reserve estimations are predictions with limited data as in the most part of the world so many geophysical surveys, drilling operations, logging operations and coring operations are essential for more reliable methane hydrate reserve estimations.

\section{References}

1. Collett, T.C. (2019). Gas hydrate production testing-knowledge gained. The Offshore Technology Conference, Houston, Texas, USA, 6-9 May 2019 (OTC-29516-MS).

2. Johnson, A.H. (2011). Global resource potential of gas hydrate-a new calculation. The $7^{\text {th }}$ International Conference on Gas Hydrates (ICGH 2011), Edinburgh, Scotland, United Kingdom, July 17-21, 2011.

3. Merey, S. (2017). Analysis of the Black Sea gas hydrates. PhD Thesis, Middle East Technical University, Ankara, Turkey.

4. Merey, S., \& Lin, C. (2020). Comparison of the Gulf of Mexico and the Mediterranean Sea gas hydrates. Gordon Research Conferences-Natural Gas Hydrate Systems, February 23-28, 2020, Galveston, TX, USA.

5. Merey, S. (2020). Gas hydrate potential of the Sea of Marmara (Under Review).

6. Boswell, R., \& Collett, T.S. (2011). Current perspectives on gas hydrate resources. Energy \& Environmental Science, 4(4), 1206-1215. https://doi.org/10.1039/c0ee00203h

7. Jongsma, D. (1974). Heat flow in the Aegean Sea. Geophysical Journal International, 37(3), 337-346. https://doi.org/10.1111/j.1365-246x.1974.tb04087.x

8. DSDP-42. (1978). Deep Sea Driling Program: Leg 42 in the Black Sea. Retrieved from (Accessed on July 20, 2020): www.deepseadrilling.org/42 1/dsdp toc.htm

9. Papatheodorou, G., Hasiotis, T., \& Ferentinos, G. (1993). Gas-charged sediments in the Aegean and Ionian Seas, Greece. Marine Geology, 112(1-4), 171-184. https://doi.org/10.1016/0025$\underline{3227(93) 90167-t}$

10. ODP Leg 160. (1995). Mediterranean Sea I: The Eastern Mediterranean Sites 963-973, 3 March-3 May 1995. Retrieved from (Accessed on October 29, 2019): www.odp.tamu.edu/publications/leg_ndx/160ndex.htm

11. Vassilev, A. (2006). Black Sea gas hydrates stability zone model (optimistic \& pessimistic assessment). CRIMEA Final Project Meeting, January 19-21, 2006, Gent, Belgium. https://doi.org/10.5593/sgem2012/s14.v3004 
12. Ruffine, L., Fandino, O., Etoubleau, J., Chron, S., Donval, J.-P., Germain, Y., \& Louis, G. (2012). Geochemical dynamics of the natural-gas hydrate system in the Sea of Marmara, Offshore Turkey. Advances in Natural Gas Technology. https://doi.org/10.5772/36343

13. Dondurur, D., Çifçi, G., Drahor, G.D. \& Coskun, S. (2011). Acoustic evidence of shallow gas accumulations and active pockmarks in the Izmir Gulf, Aegean Sea. Marine and Petroleum Geology, 28(8), 1505-1516. https://doi.org/10.1016/j.marpetgeo.2011.05.001

14. Tozer, B., Sandwell, D.T., Smith, W.H.F., Olson, C., Beale, J.R., \& Wessel, P. (2019). Global bathymetry and topography at 15 arc seconds: SRTM15+, Accepted Earth and Space Science, August 3, 2019. Retrieved from (Accessed on 20.07.2020): https://topex.ucsd.edu/cgibin/get srtm15.cgi 